Jens Tenscher $\cdot$ Christian Schicha (Hrsg.)

Talk auf allen Kanälen 
Jens Tenscher - Christian Schicha (Hrsg.)

\section{Talk auf allen Kanälen}

Angebote, Akteure und Nutzer von Fernsehgesprächssendungen

Westdeutscher Verlag 
Die Deutsche Bibliothek - CIP-Einheitsaufnahme

Ein Titeldatensatz für diese Publikation ist bei

Der Deutschen Bibliothek erhältlich

1. Auflage Oktober 2002

Alle Rechte vorbehalten

(C) Westdeutscher Verlag GmbH, Wiesbaden 2002

Lektorat: Nadine Kinne

Der Westdeutsche Verlag ist ein Unternehmen der Fachverlagsgruppe BertelsmannSpringer. www.westdeutscher-verlag.de

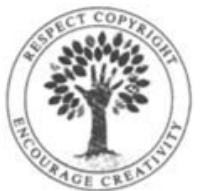

Das Werk einschließlich aller seiner Teile ist urheberrechtlich geschützt. Jede Verwertung außerhalb der engen Grenzen des Urheberrechtsgesetzes ist ohne Zustimmung des Verlags unzulässig und strafbar. Das gilt insbesondere für Vervielfältigungen, Übersetzungen, Mikroverfilmungen und die Einspeicherung und Verarbeitung in elektronischen Systemen.

Die Wiedergabe von Gebrauchsnamen, Handelsnamen, Warenbezeichnungen usw. in diesem Werk berechtigt auch ohne besondere Kennzeichnung nicht zu der Annahme, dass solche Namen im Sinne der Warenzeichen- und Markenschutz-Gesetzgebung als frei zu betrachten wären und daher von jedermann benutzt werden dürften.

Umschlaggestaltung: Horst Dieter Bürkle, Darmstadt

Umschlagbild: Jens Tenscher, Hans-Peter Wolter, Landau

Gedruckt auf säurefreiem und chlorfrei gebleichtem Papier

ISBN 978-3-531-13709-4

ISBN 978-3-322-87341-5 (eBook)

DOI $10.1007 / 978-3-322-87341-5$ 


\section{Inhalt}

Christian Schicha und Jens Tenscher

Talk auf allen Kanälen.

Eine Einführung

\section{Theoretische Implikationen}

Friedrich Krotz

Unterhaltung, die der Unterhaltung dient?

Talkshows zwischen Trash und Geschäft, Unterhaltung und Diskussionsangebot .. 39

Jens Tenscher

Talkshowisierung als Element moderner Politikvermittlung 55

Klaus Plake

Reden und Redlichkeit.

Talkshow-Rhetorik unter medienkritischem Aspekt

Lothar Mikos

Öffentlichkeit versus Privatheit.

Daily Talks als Ende der Intimität?

Udo Göttlich

Intime Bekenntnisse - konforme Kultur?

Individualität und Konformismus in der Talkshow-Unterhaltung

Wolfgang Wunden

Gesellschaftliche Integration per TV-Talk?

Medienethische Aspekte.

Kurt-Henning Schober und Dagmar Schütte

Jugendschutz und Allgemeine Programmgrundsätze bei Talkshows

im Tagesprogramm. 


\section{Formate und Inhalte}

\section{Udo Michael Krüger}

Thementrends im Talkshowangebot der neunziger Jahre.

\section{Stefano Semeria}

Die Daytime Talkshow.

Zur Erfindung eines Genres in den USA und dessen Adaption in Deutschland..... 161

\section{Hans Jürgen Wulff}

Phone-In-Shows und Therapie-Talks.

Kommunikationstheoretische Überlegungen

\section{Michael Schaffrath}

„5 Mark ins Phrasenschwein“.

Interviews, Gespräche und Talkrunden in der Sportberichterstattung

\section{Christian Schicha}

Die Inszenierung politischer Diskurse.

Beobachtungen zu Politikerauftritten in Fernsehtalkshows

\section{Tanjev Schultz}

Journalisten-Talk.

Politische Kommunikation als Punditocracy?

\section{Akteure und Strategien}

\section{Hans Meiser}

„Alltäglich, abgedroschen, selbstverständlich“?

Ein persönlicher Rückblick auf acht Jahre „Hans Meiser“

\section{Peter Imhof}

„Die Quote im Kopf“.

Innenansichten eines Daily-Talk-Moderators

\section{Bettina Fromm}

$\mathrm{Zu}$ Gast im Fernsehen.

Gesammelte Forschungsergebnisse 
Franz Machilek und Astrid Schütz

Politiker als Talkshowstars.

Talkshowgäste im Vergleich sowie Joschka Fischer als Beispiel eines

hoch variablen Selbstdarstellers 285

\section{Nutzung und Wirkung}

Maria Gerhards und Walter Klingler

Talkshownutzung und Talkshownutzer.

Ein Überblick

Ingrid Paus-Haase

Zur Bedeutung von Talkshows in der Identitätsgenese von Jugendlichen

Jana Hatzenbühler und Wolfgang Scheidt

Der Effekt liegt im Affekt.

Erwartungen, affektive Bewertungen und Nutzungsmotive von Daily-

Talkshowrezipienten.

Werner Holly

Fernsehkommunikation und Anschlusskommunikation.

Fernsehbegleitendes Sprechen über Talkshows

Carsten Brosda

Emotionen und Expressivität in Polit-Talks.

Die emotionale Dimension von Politiker-Diskussionen im Fernsehen 371

Hajo Diekmannshenke

Unterhaltung contra Information?

Zur Nutzung politischer Fernsehdiskussionen 387 